\title{
Static balance and proprioception evaluation in deaf national basketball players
}

Authors' Contribution: A Study Design B Data Collection

C Statistical Analysis

D Data Interpretation

E Manuscript Preparation

F Literature Search

G Funds Collection

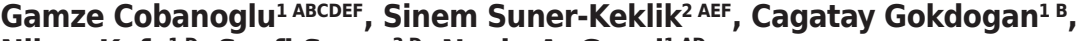 \\ Nihan Kafa ${ }^{1 D}$, Seyfi Savas ${ }^{3}$, Nevin A. Guzel ${ }^{1 \text { AD }}$ \\ ${ }^{1}$ Department of Physiotherapy and Rehabilitation, \\ Gazi University, Faculty of Health Sciences, Ankara, Turkey \\ 2 Department of Physiotherapy and Rehabilitation, \\ Sivas Cumhuriyet University, Faculty of Health Sciences, Sivas, Turkey \\ ${ }^{3}$ Department of Physical Education and Sports Teaching, \\ Gazi University, Faculty of Sports Science
}

\section{abstract}

Background: Because of the proximity of anatomical structures involved in auditory and vestibular functions, complications concerning the inner ear may lead to problems involving both systems. This study investigated whether static balance and knee proprioception in deaf basketball players are different from those in individuals with normal hearing.

Material and methods: 12 deaf national basketball players and 13 individuals with normal hearing were included. Static balance was evaluated using the Biodex-BioSway Balance System. Knee proprioception was assessed using a Dualer IQ Digital Inclinometer with the active angle repetition test.

Results: The dominant-side mediolateral stability index and non-dominant-side overall, anteroposterior, and mediolateral stability index scores of deaf basketball players in the postural stability test were different compared with those of the individuals with normal hearing $(p<0.05)$. There was no statistically significant difference between the two groups in terms of knee proprioception $(p>0.05)$.

Conclusions: Although there was no difference in knee proprioception in deaf basketball players, it is noteworthy that their postural stability was more impaired compared with that in individuals with normal hearing. Despite regular exercise, deaf basketball players had poorer balance than individuals with normal hearing. Therefore, balance and vestibular exercises should be added to the training programs of these athletes.

Key words: deaf basketball; hearing impairment; static balance; postural stability; proprioception.

\section{article details}

Article statistics:

Full-text PDF:

Copyright

Indexation:

Funding:

Conflict of interests:

Corresponding author:

Open Access License:
Word count: 2,274; Tables: 3; Figures: 0; References: 26

Received: July 2020; Accepted: February 2021; Published: March 2021

http://www.balticsportscience.com

(c) Gdansk University of Physical Education and Sport, Poland

Celdes, Clarivate Analytics Emerging Sources Citation Index (ESCI), CNKI Scholar (China National Knowledge Infrastructure), CNPIEC, DOAJ, EBSCO - Central \& Eastern European Academic Source, EBSCO - SPORTDiscus, EBSCO Discovery Service, Google Scholar, Index Copernicus, J-Gate, Naviga (Softweco, Primo Central (ExLibris), ProQuest - Family Health, ProQuest - Health \& Medical Complete, ProQuest - Illustrata: Health Sciences, ProQuest Nursing \& Allied Health Source, Summon (Serials Solutions/ProQuest, TDOne (TDNet), Ulrich's Periodicals Directory/ ulrichsweb, WorldCat (OCLC)

This research received no specific grant from any funding agency in the public, commercial, or not-for-profit sectors. Authors have declared that no competing interest exists.

Gamze COBANOGLU, PT, MSc, Department of Physiotherapy and Rehabilitation, Faculty of Health Sciences, Gazi University, Besevler/ Ankara; Emek, Bişkek Cad. 6. (eski 81. sokak), No: 206490 Çankaya/Ankara, Turkey; phone: +0905433500978; e-mail: fztgamze7@gmail.com; https://orcid.org/0000-0003-0136-3607

This is an open access article distributed under the terms of the Creative Commons Attribution-Non-Commercial-NoDerivatives 4.0 International (https://creativecommons.org/licenses/by-nc-nd/4.0/), which permits use, distribution and reproduction in any medium, provided the original work is properly cited, the use is non-commercial and is otherwise in compliance with the license. 


\section{INTRODUCTION}

Balance can be defined as the static maintenance of a support base with minimal movement and the dynamic ability to perform a task while maintaining a stable position [1]. Regulation of balance occurs through afferent sensory processing of the visual, somatosensory, and vestibular systems [2]. Somatosensory input is the primary source of sensory input to maintain balance in adults [3]. An important component of the somatosensory system is proprioception [4]. Proprioception is a central nervous system process that determines the relative position/movement of the limbs/trunk during balance [3]. These systems are integrated into the central nervous system with the purpose of producing motor responses and maintaining balance. Thus, changes in any of these sensory systems may lead to disturbances in the balance of the body [2].

Because of the proximity of anatomical structures involved in auditory and vestibular functions, problems involving both systems are likely to occur in case of complications involving the inner ear. In individuals with sensorineural hearing loss, sensory changes occur in the vestibular system due to possible damage to the inner ear. Because the vestibular system is one of the sensory systems responsible for regulating balance, impaired regulation may occur in individuals with sensorineural hearing loss or this regulation may not be coordinated compared with that in normal hearing [5].

Athletes with hearing impairment do not experience any physical deprivation and can participate in competitive sports tailored to these individuals without any limitations. Communication barriers associated with deafness are the only factors that distinguish them from other athletes. The term "deaf" is defined by the International Sports Committee for the Deaf as the perception of sound only at $55 \mathrm{~dB}$ or more through the ear that hears better [6]. At present, Paralympic and Deaflympic sports take place with intense participation, and basketball is one of the most popular sports [7]. Basketball is characterized by activities ranging from low-intensity running and walking to maximum load sprints and jumps; it involves balance instability, including acceleration and slowdowns specific to basketball; it involves sudden shifts, defense, boxing out and dribbling and requires physical contact with the opponent. These actions are usually performed in a very limited space and require very fast movement, high coordination ability, and appropriate strength [8]. Having good balance when applying these skills results in better performance and reduces the risk of injury [9]. There is evidence that proprioception plays an important role in improving sports performance [10] and preventing injuries [11].

While balance and proprioception are important in healthy basketball players, they gain more importance in hearing-impaired athletes because of the impact of the vestibular system. Although there are studies in the literature that assess the balance in hearingimpaired children, no study has evaluated balance and proprioception in deaf national basketball players and compared them with individuals with normal hearing. The purpose of this study was to determine whether static balance and knee proprioception of players of the deaf national basketball team are different from those in the individuals with normal hearing.

\section{MATERIAL AND METHOD}

\section{PARTicipants}

The study included 12 deaf basketball players who had been engaged in active basketball for at least 2 years and 13 individuals with normal hearing with similar demographic characteristics. The participants' demographic characteristics are shown in Table 1. Those who underwent surgery of the lower extremities, those who had deformities of the lower extremities, those with neurological problems, those with a systemic disease, those who 
had had knee problems in the past 3 months, those who had knee pain, and those who had vision problems to the extent that they required the use of glasses in their daily life were not included in the study. All participants signed an informed consent form. Approval for the study was obtained from the ethics committee of our university (Date: 02/06/2018, No.: 77082166-302.08.01).

Table 1. Comparison of the participants' demographic characteristics

\begin{tabular}{|c|c|c|c|}
\hline & $\begin{array}{l}\text { Deaf basketball players } \\
\qquad(\mathrm{n}=12)\end{array}$ & $\begin{array}{l}\text { Individuals with normal hearing } \\
\qquad(\mathrm{n}=13)\end{array}$ & $\mathrm{p}$ \\
\hline Age (years) Median (IQR) & $22.5(21 / 26.5)$ & $24(22 / 25)$ & 0.546 \\
\hline Body weight $(\mathrm{kg})$ Median (IQR) & $81.6(79.2$ / 87.5) & $75.3(73.3 / 81.9)$ & 0.115 \\
\hline Height (cm) Median (IQR) & $183(180.5$ / 192) & $180(175 / 184)$ & 0.134 \\
\hline BMI $\left(\mathrm{kg} / \mathrm{cm}^{2}\right)$ Median (IQR) & $24.7(22.25 / 26.25)$ & $23.4(21.9 / 25.6)$ & 0.446 \\
\hline \multirow[b]{3}{*}{ Training experience (vears) } & 12 & 13 & \\
\hline & 0 & 0 & \\
\hline & $11(8.5 / 14.5)$ & & \\
\hline
\end{tabular}

BMI: Body Mass Index, IQR: Interquartile range

\section{MeASUREMENTS}

The participants' static balance was evaluated using the Biodex-BioSway Balance System (SD 950-340, Biodex Medical Systems, Inc., Shirley, NY, USA) during a postural stability test. Participants were asked to maintain their balance for $20 \mathrm{~s}$ while standing on one leg. Three measurements were performed following a trial test. The test started with the dominant side and was repeated for both legs. The overall stability index (OSI), the anteroposterior stability index (APSI) and the mediolateral stability index (MLSI) scores were obtained. These scores indicate the deviation between the participant's center of gravity and the center of the support base. Lower scores indicate a low deviation and good postural stability [12].

Knee proprioception assessment was performed using a Dualer IQ Digital Inclinometer (J-Tech Medical, Midvale, UT, USA) with an active pain repetition test in a closed kinetic chain position in the standing position. One part of the inclinometer was fixed with a strap along the joint line to the lower third of the lateral side of the thigh, and the other part was placed in the upper third of the lateral face of the lower leg along the joint line. The test started when the knee was in the extension position, and individuals were instructed to squat on one leg until they reached the target angle. When they reached $30^{\circ}$, which was the target angle, they were asked to stand in that position and maintain it for $5 \mathrm{~s}$. They were then asked to return to the starting position (full knee extension). The target angle was reached for a total of three times; the participants were then asked to reach the target angle three times as correctly as possible, and angular deviations were recorded and averaged [13].

\section{STATISTICAL ANALYSIS}

Statistical analysis was performed using SPSS, version 22.0. Normal distribution of parameters was examined using visual (histograms and probability charts) and analytical methods (Kolmogorov-Smirnov/Shapiro-Wilk tests). Descriptive analysis was performed using median and interquartile ranges for variables without normal distribution. Variables were compared using the Mann-Whitney U test between groups, as parameters were determined to show no normal distribution. p-values below 0.05 were considered statistically significant. 


\section{RESULTS}

There was no difference in height, body weight, and body mass index between the deaf basketball players and individuals with normal hearing ( $p>0.05$, Table 1$)$.

Postural stability in the deaf basketball players was different in terms of the dominantside MLSI and the non-dominant-side OSI, APSI and MLSI scores $(\mathrm{p}<0.05$, Table 2$)$. There was no difference in terms of the dominant-side OSI and APSI scores ( $p>0.05$, Table 2 ). Postural stability in the individuals with normal hearing was better than that in the deaf basketball players.

There was no statistical difference in knee proprioception between the deaf basketball players and the individuals with normal hearing ( $p>0.05$, Table 3). Both groups had similar proprioceptive senses.

Table 2. Comparison of deaf basketball players and the individuals with normal hearing in terms of postural stability

\begin{tabular}{lcccc}
\hline & & $\begin{array}{c}\text { Deaf basketball players } \\
\text { Median (IQR) }\end{array}$ & $\begin{array}{c}\text { Individuals with normal } \\
\text { hearing Median (IQR) }\end{array}$ & $p$ \\
\hline Dominant side & OSI & $1.05(0.80 / 1.35)$ & $0.80(0.70 / 0.90)$ & 0.066 \\
& APSI & $0.85(0.65 / 1.05)$ & $0.70(0.50 / 0.80)$ & 0.206 \\
\hline Non-dominant side & MLSI & $0.45(0.40 / 0.50)$ & $0.30(0.30 / 0.40)$ & $0.037^{*}$ \\
& OSI & $1.35(1.05 / 1.60)$ & $0.90(0.80 / 1.00)$ & $0.006^{*}$ \\
& APSI & $0.90(0.85 / 1.25)$ & $0.70(0.60 / 0.80)$ & $0.006^{*}$ \\
\hline
\end{tabular}

OSI: Overall stability index, APSI: Anteroposterior stability index, MLSI: Mediolateral stability index, IQR: Interquartile range, $* p<0.05$

Table 3. Comparison of deaf basketball players and the individuals with normal hearing in terms of proprioception

\begin{tabular}{lccc} 
& $\begin{array}{c}\text { Deaf basketball players Median } \\
\text { (IQR) }\end{array}$ & $\begin{array}{c}\text { Individuals with normal hearing } \\
\text { Median (IQR) }\end{array}$ & $\mathrm{p}$ \\
\hline Dominant side & $1.83(1.33 / 2.66)$ & $2(1 / 3)$ & 0.763 \\
Non-dominant side & $2(1.32 / 2.66)$ & $0.66(0.33 / 2)$ & 0.076 \\
\hline
\end{tabular}

IQR: Interquartile range

\section{DISCUSSION}

To the best of our knowledge, this is the first study to evaluate deaf basketball players in terms of static balance and proprioception and compare them with individuals with normal hearing. The results showed that both these parameters were better in individuals with normal hearing than in hearing-impaired basketball players; however, both had similar proprioceptive senses.

Balance is achieved by coordination of inputs from visual, vestibular, and somatosensory systems [5]. The somatosensory system provides multiple inputs to the central nervous system from various muscle and connective tissue receptors that contribute to proprioception. The somatosensory system also allows the continuation of stability through the combination of vestibular and visual information to perform a specific task in a particular environment and ensures efficient, accurate, and effective movement of body parts [3]. The importance of the sensation of proprioception in maintaining balance leads to the need for evaluation of this parameter in athletes. Our results show that highlevel basketball players with hearing impairment and individuals with normal hearing have 
similar knee proprioception. The proprioceptive characteristics of the two groups with no visual impairment were similar, which suggests that the detected impaired balance may be due to the vestibular system rather than the visual and somatosensory system, which is responsible for the coordination of balance.

Damage to some parts of the vestibulocochlear nerve, a part of the vestibular system that is one of the structures involved in the integration of balance, leads not only to sensorineural hearing loss but may also be associated with balance problems caused by damage to the branches of the vestibular nerve. This can lead to balance problems in individuals with hearing impairment [14]. Many studies in the literature have compared hearing-impaired children with individuals with normal hearing in terms of balance $[8,15$, 16]. The tests used in studies evaluating the balance function include static and dynamic tests. The most commonly used tests are conventional tests such as the one-leg standing test, Romberg test, and Berg Balance Scale. Stabilometric platforms are among the more accurate and reliable evaluation methods for analyzing static balance in hearingimpaired children, such as the test used in the current study (posturographic tests), and they include computer graphic records of changes in the center of gravity [15]. Some studies that evaluated balance reported that balance was better in hearing-impaired individuals than in individuals with normal hearing, while few studies have reported similar or poorer balance. Based on the results of the study conducted by Walicka-Cuprys et al. [15], which contradict our results, hearing-impaired children exhibit static balance superior to children with normal hearing, and these differences are especially evident in tests conducted with closed eyes. In addition, the authors discuss that sensory stimuli, especially proprioceptive and to a lesser extent visual stimulus, are better processed in postural reactions in hearing-impaired children than in their healthy peers [15]. However, in our study, we determined that proprioception is similar in individuals who do not have loss of vision requiring glasses or any pathologies involving the musculoskeletal system. In contrast, Gayle and Pohlman [16] reported that the general balance in hearing-impaired children is significantly inferior compared with that in children with normal hearing. Melo et al. [5] reported that students with hearing loss have more instability in postural control than those with normal hearing. Similarly, Sousa et al. [17] and Ebrahimi et al. [18] reported that children with hearing impairment have a lower balance performance than children with normal hearing. Similarly to these results in hearing-impaired children, our study shows that although hearing-impaired basketball players with a mean age of 22.5 years perform regular sports, their postural stability is still poor compared with that in individuals with normal hearing. Szulc et al. [19] stated that if they do not have other health problems, they will not limit opportunities to develop physical fitness for deaf women with hearing impairment. Buśko et al. [20] also found that doing sports improves the physical fitness of deaf people in comparison with untrained deaf people. In our study, the worsening of balance, which is one of the physical fitness parameters, in individuals who do sports may be due to the lack of sufficient focus on improving balance in the development period and training programs of deaf basketball player. Based on the results of another study that evaluated balance in deaf athletes, the importance of balance training in hearing-impaired individuals is emphasized, and it is suggested that training should be planned for athletes with different sensory inputs and appropriate strategies to improve balance. In this study, hearing-impaired athletes in different branches were evaluated, but these results were not compared with a healthy control group [21].

High-level basketball players are expected to display a high level of motor coordination because scoring in a basketball game is relatively difficult due to the movements of the opponents, the duration and the rules of the game, the effect of fatigue, and other elements. Balance is a coordination ability [22]. Because of these factors, athletes are expected to have good balance. However, the expected result was not achieved in this 
study. Problems in balance can affect athletic performance and increase the risk of injury [23]. A study found that low static balance performance and increased postural oscillation are associated with a higher incidence of ankle sprain in basketball players [24]. The assessment of balance, which is so closely associated with both a risk of injury and athletic performance, is highly important in healthy basketball players as well as in hearingimpaired basketball players. Based on these results, we believe that the training programs of hearing-impaired basketball players should be reviewed, and appropriate exercises should be added to eliminate postural stability loss. A review reported that vestibular exercises improve postural control and balance in children with sensorineural hearing loss [25]. Another study of hearing-impaired karate players showed that both stabilization and balance exercises improve balance performance [26]. Based on these results, we think that balance and vestibular exercises included in the daily lives and training programs of hearing-impaired basketball athletes will improve their postural stability.

An important limitation of our study is that only healthy individuals with normal hearing function were included as the control group. The results would be better interpreted if there was a comparison with basketball players with normal hearing function. In addition, only static balance was evaluated, and dynamic balance was not evaluated in the study. Additional studies are needed to evaluate and compare all balance parameters in deaf basketball players and healthy basketball players.

\section{CONCLUSIONS}

In this study, we found that deaf basketball players had poor static balance compared with individuals with normal hearing but similar proprioceptive senses. These results confirm the need to examine postural control to determine the degree of deficit in poor balance function, which may lead to injury or a decrease in performance, and also the need for intervention to eliminate the balance deficit in deaf basketball players. Balance and vestibular exercises should be added to the training programs of deaf basketball players to eliminate this deficit, reduce the risk of injury, and improve athletic performance.

\section{REFERENCES}

[1] Bressel E, et al. Comparison of static and dynamic balance in female collegiate soccer, basketball, and gymnastics athletes. J Athl Train. 2007;42(1):42.

[2] Melo RS, et al. Does the practice of sports or recreational activities improve the balance and gait of children and adolescents with sensorineural hearing loss? A systematic review. Gait \& Posture. 2020;77:144-155. https://doi. org/10.1016/j.gaitpost.2020.02.001

[3] Ogard WK. Proprioception in sports medicine and athletic conditioning. Strength Cond J. 2011;33(3):111-118. https:// doi.org/10.1519/SSC.0b013e31821bf3ae

[4] Hrysomallis C. Relationship between balance ability, training and sports injury risk. Sports Med. 2007;37(6): 547-556. https://doi.org/10.2165/00007256-200737060-00007

[5] Melo RdS, et al. Postural control assessment in students with normal hearing and sensorineural hearing loss. Braz J Otorhinolaryng. 2015;81(4):431-438. https://doi.org/10.1016/j.bjorl.2014.08.014

[6] Kurková P, Válková H, Scheetz N. Factors impacting participation of European elite deaf athletes in sport. J Sport Sci. 2011;29(6):607-618. https://doi.org/10.1080/02640414.2010.548821

[7] Sobko I. Characteristics of competitive activity of qualified basketball with hearing impairment compare to qualified healthy basketball player. Phys Educ Student. 2013;17(4):82-86.

[8] Bouteraa I, et al. Effects of combined balance and plyometric training on athletic performance in female basketball players. J Strength Cond Res. 2018.

[9] Notarnicola A, et al. Effects of training on postural stability in young basketball players. Muscles Ligaments Tendons J. 2015;5(4):310. https://doi.org/10.11138/mltj/2015.5.4.310

[10] Han J, et al. Assessing proprioception: A critical review of methods. J Sport Health Sci. 2016;5(1):80-90. https://doi. org/10.1016/j.jshs.2014.10.004

[11] Riva D, et al. Proprioceptive training and injury prevention in a professional men's basketball team: A six-year prospective study. J Strength Cond Res. 2016;30(2):461-475. https://doi.org/10.1519/JSC.0000000000001097

[12] Hinman MR. Factors affecting reliability of the Biodex Balance System: A summary of four studies. J Sport Rehabil. 2000;9(3):240-252. https://doi.org/10.1123/jsr.9.3.240 
[13] Suner-Keklik S, et al. The validity and reliability of knee proprioception measurement performed with inclinometer in different positions. J Sport Rehabil. 2017;26(6):1-15.

[14] Soori Z, Heyrani A, Rafie F. Exercise effects on motor skills in hearing-impaired children. Sport Sci Health. 2019;15(3):635-639. https://doi.org/10.1007/s11332-019-00564-y

[15] Walicka-Cupryś K, et al. Balance assessment in hearing-impaired children. Res Development Disabil. 2014;35(11):27282734. https://doi.org/10.1016/j.ridd.2014.07.008

[16] Gayle GW, Pohlman RL. Comparative study of the dynamic, static, and rotary balance of deaf and hearing children Percept Motor Skills, 1990;70(3):883-888. https://doi.org/10.2466/pms.1990.70.3.883

[17] de Sousa AMM, de França Barros J, de Sousa Neto BM. Postural control in children with typical development and children with profound hearing loss. Int J General Med. 2012;5:433-439. https://doi.org/10.2147/IJGM.S28693

[18] Ebrahimi A-A, et al. Postural control in deaf children. Acta Medica Iran. 2017;55(2):115-122.

[19] Szulc AM, et al. The biomechanical characteristics of elite deaf and hearing female soccer players: comparative analysis. Acta Bioeng Biomech. 2017;19(4):127-133.

[20] Buśko K, Kopczyńska J, Szulc A. Physical fitness of deaf females. Biomed Hum Kinet. 2020;12(1):101-104. https:// doi.org/10.2478/bhk-2020-0013

[21] Akınoğlu, B. and T. Kocahan, The effect of deafness on the physical fitness parameters of elite athletes. Journal of exercise rehabilitation, 2019. 15(3): p. 430. https://doi.org/10.12965/jer.1938100.050

[22] Struzik A, Zawadzki J, Pietraszewski B. Balance disorders caused by running and jumping occurring in young basketball players. Acta Bioeng Biomech. 2015;17(2):103-109.

[23] Zemková E. Assessment of balance in sport: science and reality. Serb J Sport Sci. 2011;5(4):127-139.

[24] Bird SP, Markwick WJ. Musculoskeletal screening and functional testing: considerations for basketball athletes. Int J Sport Phys Therap. 2016;11(5):784.

[25] Melo R.S, et al. Vestibular rehabilitation exercises programs to improve the postural control, balance and gait of children with sensorineural hearing loss: A systematic review. Int J Pediatr Otorhinolaryng. 2019;127:109650. https:// doi.org/10.1016/j.ijporl.2019.109650

[26] Akınoğlu B, Kocahan T. Stabilization training versus equilibrium training in karate athletes with deafness. J Exerc Rehabil. 2019;15(4):576-583. https://doi.org/10.12965/jer.1938306.153 